\title{
Impact of genetic variant BDNF (Val66Met) on brain structure and function
}

\author{
Zhe-Yu Chen ${ }^{*}$, Kevin Bath ${ }^{*}$, Bruce McEwen ${ }^{\dagger}$, Barbara Hempstead ${ }^{\ddagger}$, and Francis Lee ${ }^{*}, \S, 1$ \\ *Department of Psychiatry, Weill Medical College of Cornell University, New York, NY 10021 \\ †Laboratory of Neuroendocrinology, The Rockefeller University, New York, NY 10021 \\ ‡Division of Hematology, Department of Medicine, Weill Medical College of Cornell University, New \\ York, NY 10021, USA \\ $\S$ Department of Pharmacology, Weill Medical College of Cornell University, New York, NY 10021, \\ USA
}

\begin{abstract}
A common single-nucleotide polymorphism in the human brain-derived neurotrophic factor (BDNF) gene, a methionine (Met) substitution for valine (Val) at codon 66 (Val66Met), is associated with alterations in brain anatomy and memory, but its relevance to clinical disorders is unclear. We generated a variant BDNF mouse (BDNFMet/Met) that reproduces the phenotypic hallmarks in humans with the variant allele. Variant $\mathrm{BDNF}_{\text {Met }}$ was expressed in brain at normal levels, but its secretion from neurons was defective. In this context, the $\mathrm{BDNF}^{\mathrm{Met} / \mathrm{Met}}$ mouse represents a unique model that directly links altered activity-dependent release of BDNF to a defined set of in vivo consequences. Our subsequent analyses of these mice elucidated a phenotype that had not been established in human carriers: increased anxiety. When placed in conflict settings, BDNFMet/Met mice display increased anxiety-related behaviours that were not normalized by the antidepressant, fluoxetine. A genetic variant BDNF may thus play a key role in genetic predispositions to anxiety and depressive disorders.
\end{abstract}

Brain-derived neurotrophic factor (BDNF), a molecule known to regulate neuronal survival and plasticity, is widely expressed in the developing and adult mammalian brain (Huang \& Reichardt 2001, Chao 2003). In addition to regulating neuronal survival and differentiation, BDNF participates in activity-dependent plasticity processes such as long-term potentiation, learning and memory (Lu 2003a). Recently, a common single nucleotide polymorphism (SNP) in the BDNF gene leading to a valine to methionine substitution at position 66 in the prodomain (Val66Met) has been identified and shown to influence human hippocampal volume and memory (Egan et al 2003). This BDNF SNP only exists in human and is found to be also associated with altered susceptibility to a variety of neuropsychiatric disorders (Momose et al 2002, Neves-Pereira et al 2002, Sklar et al 2002, Ventriglia et al 2002, Sen et al 2003). This polymorphism in the BDNF gene represents an important initial example of a role for neurotrophins in behavioural processes in humans. This review will focus on the behavioural consequences of this variant form of BDNF in humans, and compare and contrast these findings with those in newly generated mouse model containing this variant BDNF SNP.

\footnotetext{
${ }^{1}$ This paper was presented at the symposium by Francis Lee, to whom correspondence should be addressed.
} 


\section{Molecular mechanism underlying variant $\mathrm{BDNF}_{\text {Met }}$}

The actions of BDNF are dictated by two classes of cell surface receptors, the TrkB receptor tyrosine kinase and the $\mathrm{p} 75$ neurotrophin receptor ( $\left.\mathrm{p} 75^{\mathrm{NTR}}\right)$, a member of the tumour necrosis factor (TNF) receptor superfamily (Chao 2003). BDNF binding to TrkB receptor produces neurotrophic responses through rapid activation of the PI3 kinase, Ras/MAPK and PLC $\gamma$ pathways, thus influence transcriptional events that has multiple effects on cell cycle, neurite outgrowth and synaptic plasticity (Qui \& Green 1991, Traverse et al 1992, Cowley et al 1994, Mazzucchelli et al 2002, Rosenblum et al 2002, Chao et al 2006). Signal transduction through p75 independently gives rise to increase in JNK (c-Jun N-terminal kinase) and NF$\kappa \mathrm{B}$ (nuclear factor $\kappa \mathrm{B}$ ), thus triggering apoptosis (Roux \& Barker 2002). Consistent with the critical role of BDNF in synaptic plasticity, BDNF is synthesized and released in an activitydependent manner ( $\mathrm{Lu} 2003 \mathrm{~b}$ ). In the mammalian brain, BDNF is synthesized as a precursor called proBDNF, which is proteolytically cleaved to generate mature BDNF. ProBDNF may preferentially bind $\mathrm{p} 75^{\mathrm{NTR}}$, whereas mature BDNF preferentially binds TrkB receptor (Lee et al 2001, Teng et al 2005).

The molecular mechanisms underlying altered $\mathrm{BDNF}_{\text {Met }}$ function have begun to be studied primarily in in vitro cell culture systems. The Met substitution in the prodomain was shown in neurosecretory cells and primary cultured neurons to lead to three trafficking defects: (1) decreased variant BDNF distribution into neuronal dendrites; (2) decreased variant BDNF targeting to secretory granules; and (3) subsequent impairment in regulated secretion (Egan et al 2003, Chen et al 2004, Chen et al 2005). In addition, when expressed together in the same cell, $\mathrm{BDNF}_{\mathrm{Met}}$ alters the trafficking of wild-type $\mathrm{BDNF}\left(\mathrm{BDNF}_{\mathrm{Val}}\right)$ through the formation of heterodimers that are less efficiently sorted into the regulated secretory pathway (Chen et al 2004). These initial findings are consistent with previous studies indicating that the prodomain of neurotrophins plays an important role in regulating their intracellular trafficking to secretory pathways (Suter et al 1991). Together, these in vitro studies with $\mathrm{BDNF}_{\text {Met }}$ point to the presence of a specific trafficking signal in the BDNF prodomain region encompassing the Met substitution that is required for efficient BDNF sorting.

Recently, a trafficking protein, sortilin, was shown to be necessary for the efficient sorting of BDNF to the regulated secretory pathway. Sortilin interacts specifically with BDNF in a region encompassing the Met substitution (Chen et al 2005). Replacement of Met at this position led to decreased interaction of BDNF with this trafficking protein and suggests that decreased protein-protein interaction between BDNF and the trafficking machinery as one plausible molecular model for the secretion defect observed with the variant BDNF. This variant BDNF provides an example of how appropriate trafficking of BDNF may have a significant impact on the physiological responses to neurotrophins.

However, fundamental questions remain as to how these in vitro effects relate to the in vivo consequences of this SNP in humans. The main caveat to these in vitro overexpression studies has been that overexpression of neurotrophins has itself led to altered trafficking fates in cultured neurons (Farhadi et al 2000). As the majority of BDNF is released from the regulated secretory pathway in neurons, impaired regulated secretion of $\mathrm{BDNF}_{\mathrm{Met}}$ represents a significant decrease in available BDNF.

It also remains possible that there are additional defects in $\mathrm{BDNF}_{\text {Met }}$ processing that may contribute to the observed deficits, although in vitro studies in neurons suggest no defect in $\mathrm{BDNF}_{\text {Met }}$ processing (Egan et al 2003, Chen et al 2004). It has been reported that tissue plasminogen activator, by activating the extracellular protease plasmin, converts proBDNF to the mature BDNF, and that such conversion is critical for late-phase long-term potentiation in the mouse hippocampus (Pang et al 2004). Given that proBDNF preferentially activates 
p75 ${ }^{\mathrm{NTR}}$ over TrkB receptor, it is likely that proteolytic conversation of proBDNF may be implicated in BDNF functioning.

\section{Variant $B D N F_{\text {Met }}$ and behavioural impairments}

Until recently, no genetic associations had been identified linking neurotrophin genes to human cognitive functioning. Given BDNF's established role in mediating processes related to learning and memory (Korte et al 1995, Patterson et al 1996, Desai et al 1999), this increased susceptibility to cognitive impairment suggests that the variation in BDNF may play a role in the development of neuropsychiatric disorders as well as affect nervous system functioning.

However, in any study attempting to associate a gene with pathology or behavioural variation, it is often unclear how the change in genotype results in the phenotypic change. This is especially difficult when attempting to link a change in genotype with a discrete change in cognitive functioning. It is possible that the identified genetic variant has a direct effect on cognition, but it is also plausible that the genetic variation mediates an effect through some other downstream functional change, or through the regulation of some other gene. These caveats must be kept in mind during this discussion. In addition, the majority of studies that have been conducted to date have either excluded subjects not of European descent, or have removed other ethnic groups prior to data analysis.

One of the most reliable effects observed in carriers of the Met allele (Val/Met) is a difference in hippocampal morphology. In studies of brain morphometry using structural magnetic resonance imaging (MRI) scans, Val/Met individuals have repeatedly been shown to have a smaller hippocampal volume relative to controls who are homozygous for $\mathrm{Val}$ allele (Val/Val) (Pezawas et al 2004, Szeszko et al 2005, Bueller et al 2006, Frodl et al 2007). This difference may be related to the role that BDNF and its receptors play in the development as well as continued plasticity of the brain (Huang \& Reichardt 2001, Lu et al 2005). Despite a wealth of information on individuals heterozygous for the Met polymorphism, little information exists for individuals who are homozygous for the Met allele (Met/Met) as this genotype is rare in the general population, comprising only $4 \%$ of people in Caucasian populations (Shimizu et al 2004, Gratacos et al 2007). In addition to effects on the hippocampus, studies have also shown decreased volume in the dorsolateral prefrontal cortex, an area associated with planning and higher order cognitive functioning, as well subcortical regions such as the caudate nucleus in carriers of the Met allele (Pezawas et al 2004). Recently it was found that Met allele carriers having smaller temporal and occipital lobar grey matter volumes (Ho et al 2006).

One of the common behavioural phenotypes associated with the variant $\mathrm{BDNF}_{\mathrm{Met}}$ is impairment of higher cognitive abilities. Individuals with the Val/Met genotype have been shown to perform more poorly than control subjects $(\mathrm{Val} / \mathrm{Val})$ on memory tasks that rely heavily on the hippocampus (Egan et al 2003, Hariri et al 2003). On the basis of batteries of neuropsychological tests, carriers of the Met allele (Val/Met and Met/Met) were shown to perform worse on tasks that involved recalling places and events, but did not differ from Val/ Val individuals on tasks that have been classically shown to be less hippocampal-dependent, such as word learning and planning tasks (Egan et al 2003, Hariri et al 2003). The pattern of brain activation in Val/Met individuals also significantly differed from that of $\mathrm{Val} / \mathrm{Val}$ subjects during tasks that rely on the hippocampus. Using functional MRI (fMRI), Hariri et al (2003) showed that during a place recognition task, a task that has been shown to result in strong hippocampal activation (Gabrieli et al 1998, Schacter et al 1999, Schacter \& Wagner 1999), individuals with the Val/Met genotype had significantly lower levels of activation compared to $\mathrm{Val} / \mathrm{Val}$ individuals during both the encoding and retrieval portions of the task. In a similar functional imaging study, Egan et al (2003) employed a task that required individuals to remember a set of stimuli and recall the stimulus that had been presented two stimuli prior to 
the current stimulus (N-back task), a paradigm that typically results in suppression of the hippocampus. They found that individuals with the Met/Met genotype did not show the same level of hippocampal suppression as subjects with the $\mathrm{Val} / \mathrm{Val}$ or $\mathrm{Val} / \mathrm{Met}$ genotypes. These findings taken together suggest that carriers of the Met allele have a selective impairment in hippocampal-dependent memory.

Anxiety is a common symptom among most psychiatric disorders. Several recent studies have looked at the relationship between $\mathrm{BDNF}_{\mathrm{Met}}$ and trait anxiety. The results have been conflicting, with the Val allele associated with vulnerability in one study and the Met allele designated as the 'risk' allele in another study (Sen et al 2003, Jiang et al 2005, Lang et al 2005). Inconsistency across genetic studies may be attributable to sampling and measurement issues, genetic heterogeneity due to differential sampling of populations or low frequency of homozygous Met carriers, which may lessen the effect size of any particular association. It may also relate to a failure to take into account relevant gene-by-gene and gene-by-environment interactions. A recent investigation found the association between incident stroke and depression with the strongest association for met/met genotype participants (Kim et al 2007). So this study provides evidence for a gene-environment interaction with respect to the impact of stroke on depression. Another study revealed a significant three-way interaction between BDNF genotype, 5-HTTLPR, and maltreatment history in predicting depression (Kaufman et al 2006). Children with the $B_{D N F}$ Met allele and two short alleles of 5-HTTLPR had the highest depression scores, but the vulnerability associated with these two genotypes was only evident in the maltreated children.

\section{Variant BDNF Met $_{\text {knock-in mouse }}$}

Recently, a variant BDNF mouse (BDNFMet/Met) that reproduces the phenotypic hallmarks in human with this BDNF SNP was generated (Chen et al 2006). The expression of $\mathrm{BDNF}_{\mathrm{Met}}$ is regulated by endogenous BDNF promoters in the $\mathrm{BDNF}_{\text {Met }}$ knock-in mouse, which fully mimic the human $\mathrm{BDNF}_{\text {Met }}$ polymorphism. The $\mathrm{BDNF}_{\text {Met }}$ knock-in mice has allowed for assessment of the in vivo consequences of $\mathrm{BDNF}_{\text {Met }}$ not only for biochemical but also anatomical and behavioural measures.

Initial secretion studies were performed on neurons obtained from the $\mathrm{BDNF}_{\mathrm{Met}}$ mice, and BDNF in the resultant media was measured by enzyme-linked immunosorbent assay (ELISA). There was a significant decrease in activity-dependent secretion of endogenous BDNF from $\mathrm{BDNF}^{\mathrm{Met} / \mathrm{Met}}$ mice ( $\sim 30 \%$ decrease). As the majority of BDNF is released from the regulated secretory pathway in neurons, impaired regulated secretion from BDNF ${ }^{\text {Met/Met }}$ neurons represents a significant decrease in available BDNF.

Subsequent anatomical analyses showed there was a significant decrease in hippocampal volume in both $\mathrm{BDNF}^{+/ \mathrm{Met}}$ and $\mathrm{BDNF}^{\mathrm{Met} / \mathrm{Met}}$ mice. Furthermore, Golgi staining was used to visualize individual dentate gyrus neurons of the hippocampus. At 8 weeks of age, there was no difference in the cell soma area among $\mathrm{BDNF}_{\mathrm{Met}}$ mice and their littermate controls but a decrease in dendritic arbour complexity in $\mathrm{BDNF}_{\mathrm{Met}}$ mice. Behavioural studies determined that there was a specific impairment in hippocampal contextual fear conditioning in both $\mathrm{BDNF}^{+/ \mathrm{Met}}$ and BDNF${ }^{\mathrm{Met} / \mathrm{Met}}$ mice, whereas there was no difference in cue-dependent fear conditioning. $\mathrm{BDNF}_{\mathrm{Met}}$ mice thus appear to replicate the two hallmark alterations in hippocampal anatomy and hippocampal-dependent learning as human carriers of the $\mathrm{BDNF}_{\mathrm{Met}}$ allele. These results suggest that $\mathrm{BDNF}_{\text {Met }}$ mice are a valid animal model for the human variant BDNF SNP.

Subsequent analyses of these mice elucidated a phenotype that had not been established in human carriers: increased anxiety. When placed in conflict settings, $\mathrm{BDNF}^{\mathrm{Met} / \mathrm{Met}}$ mice display increased anxiety-related behaviours in three separate tests and thus provide a genetic link 
between BDNF and anxiety. Human genetic association studies have been inconclusive as to the contribution of this SNP to with increased anxiety. Two main differences in the mouse study design probably contributed to discerning this anxiety-related phenotype. First, mice were subjected to conflict tests to elicit the increased anxiety-related behaviour, whereas human studies relied on questionnaires. Second, the anxiety-related phenotype was only present in mice homozygous for the Met allele, which suggested that association studies that focused primarily on humans heterozygous for the Met allele may not detect an association.

The form of anxiety elicited in these BDNF ${ }^{\mathrm{Met} / \mathrm{Met}}$ mice was not responsive to a common selective serotonin reuptake inhibitor (SSRI). These results suggest that humans with this allele may not have optimal responses to this class of antidepressants. Currently, there are no reliable genetic or non-genetic biomarkers to predict who will respond to an SSRI. The transgenic $\mathrm{BDNF}^{\mathrm{Met} / \mathrm{Met}}$ mouse may serve as a valuable model to identify novel pharmacological approaches to treating anxiety symptoms that underlie many neuropsychiatric disorders.

\section{Conclusions}

The human genetic variant BDNF (Val66Met) represents the first example of neurotrophin family member, has been linked to anatomical and behavioural phenotypes in humans. However, its relevance to clinical disorders is unclear. The generation of $\mathrm{BDNF}_{\text {Met }}$ mouse model to test in a more controlled and precise manner, than in human studies, the contribution of this variant BDNF SNP to neuropsychiatric disease processes. In all, these findings indicate a new direction in therapeutic strategies to rescue anxiety symptoms in humans with this polymorphic allele. Drug discovery strategies to increase BDNF release from synapses or to prolong the half-life of secreted BDNF may improve therapeutic responses for humans with this common BDNF polymorphism.

\section{References}

Bueller JA, Aftab M, Sen S, Gomez-Hassan D, Burmeister M, Zubieta JK. BDNF Val(66)Met Allele Is Associated with Reduced Hippocampal Volume in Healthy Subjects. Biol Psychiatry 2006;59:812815. [PubMed: 16442082]

Chao MV. Neurotrophins and their receptors: a convergence point for many signaling pathways. Nat Rev Neurosci 2003;4:299-309. [PubMed: 12671646]

Chao MV, Rajagopal R, Lee FS. Neurotrophin signalling in health and disease. Clin Sci (Lond) 2006;110:167-173. [PubMed: 16411893]

Chen ZY, Patel PD, Sant G, et al. Variant brain-derived neurotrophic factor (BDNF) (Met66) alters the intracellular trafficking and activity-dependent secretion of wild-type BDNF in neurosecretory cells and cortical neurons. J Neurosci 2004;24:4401-4411. [PubMed: 15128854]

Chen ZY, Ieraci A, Teng H, et al. Sortilin controls intracellular sorting of brain-derived neurotrophic factor to the regulated secretory pathway. J Neurosci 2005;25:6156-6166. [PubMed: 15987945]

Chen ZY, Jing D, Bath KG, et al. Genetic variant BDNF (Val66Met) polymorphism alters anxiety-related behavior. Science 2006;314:140-143. [PubMed: 17023662]

Cowley S, Paterson H, Kemp P, Marshall CJ. Activation of MAP kinase kinase is necessary and sufficient for PC12 differentiation and for transformation of NIH 3T3 cells. Cell 1994;77:841-852. [PubMed: 7911739]

Desai N, Rutherford L, Turrigiano G. BDNF regulates the intrinsic excitability of cortical neurons. Learn Mem 1999;6:284-291. [PubMed: 10492010]

Egan MF, Kojima M, Callicott JH, et al. The BDNF val66met polymorphism affects activity-dependent secretion of BDNF and human memory and hippocampal function. Cell 2003;112:257-269. [PubMed: 12553913]

Farhadi H, Mowla S, Petrecca K, Morris S, Seidah N, Murphy R. Neurotrophin-3 sorts to the constitutive secretory pathway of hippocampal neurons and is diverted to the regulated secretory pathway by 
coexpression with brain-derived neurotrophic factor. J Neurosci 2000;20:4059-4068. [PubMed: 10818141]

Frodl T, Schule C, Schmitt G, et al. Association of the Brain-Derived Neurotrophic Factor Val66Met Polymorphism With Reduced Hippocampal Volumes in Major Depression. Arch Gen Psychiatry 2007;64:410-416. [PubMed: 17404118]

Gabrieli JD, Brewer JB, Poldrack RA. Images of medial temporal lobe functions in human learning and memory. Neurobiol Learn Mem 1998;70:275-283. [PubMed: 9753602]

Gratacos M, Gonzalez JR, Mercader JM, Cid RD, Urretavizcaya M, Estivill X. Brain-Derived Neurotrophic Factor Val66Met and Psychiatric Disorders: Meta-Analysis of Case-Control Studies Confirm Association to Substance-Related Disorders, Eating Disorders, and Schizophrenia. Biol Psychiatry 2007;61:911-922. [PubMed: 17217930]

Hariri AR, Goldberg TE, Mattay VS, et al. Brain-derived neurotrophic factor val66met polymorphism affects human memory-related hippocampal activity and predicts memory performance. J Neurosci 2003;23:6690-6694. [PubMed: 12890761]

Ho BC, Milev P, O’Leary DS, Librant A, Andreasen NC, Wassink TH. Cognitive and magnetic resonance imaging brain morphometric correlates of brain-derived neurotrophic factor Val66Met gene polymorphism in patients with schizophrenia and healthy volunteers. Arch Gen Psychiatry 2006;63:731-740. [PubMed: 16818862]

Huang E, Reichardt L. Neurotrophins: Roles in neuronal development and function. Annu Rev Neurosci 2001;24:677-736. [PubMed: 11520916]

Jiang X, Xu K, Hoberman J, et al. BDNF variation and mood disorders: a novel functional promoter polymorphism and Val66Met are associated with anxiety but have opposing effects. Neuropsychopharmacology 2005;30:1353-1361. [PubMed: 15770238]

Kaufman J, Yang BZ, Douglas-Palumberi H, et al. Brain-derived neurotrophic factor-5-HTTLPR gene interactions and environmental modifiers of depression in children. Biol Psychiatry 2006;59:673680. [PubMed: 16458264]

Kim JM, Stewart R, Kim SW, et al. BDNF genotype potentially modifying the association between incident stroke and depression. Neurobiol Aging. 2007In press

Korte M, Carroll P, Wolf E, Brem G, Thoenen H, Bonhoeffer T. Hippocampal long-term potentiation is impaired in mice lacking brain-derived neurotrophic factor. Proc Natl Acad Sci USA 1995;92:88568860. [PubMed: 7568031]

Lang UE, Hellweg R, Kalus P, et al. Association of a functional BDNF polymorphism and anxiety-related personality traits. Psychopharmacology (Berl) 2005;180:95-99. [PubMed: 15918078]

Lee R, Kermani P, Teng KK, Hempstead BL. Regulation of cell survival by secreted pro-neurotrophins. Science 2001;294:1945-1948. [PubMed: 11729324]

Lu B. BDNF and activity-dependent synaptic modulation. Learn Mem 2003a;100:86-98.

Lu B. Pro-region of neurotrophins: role in synaptic modulation. Neuron 2003b;39:735-738. [PubMed: 12948441]

Lu B, Pang PT, Woo NH. The yin and yang of neurotrophin action. Nat Rev Neurosci 2005;6:603-614. [PubMed: 16062169]

Mazzucchelli C, Vantaggiato C, Ciamei A, et al. Knockout of Erk1 MAP kinase enhances synaptic plasticity in the striatum and facilitates striatal mediated learning and memory. Neuron 2002;34:807820. [PubMed: 12062026]

Momose Y, Murata M, Kobayashi K, et al. Association studies of multiple candidate genes for Parkinson's disease using single nucleotide polymorphisms. Ann Neurol 2002;51:133-136. [PubMed: 11782995]

Neves-Pereira M, Mundo E, Muglia P, King N, Macciardi F, Kennedy J. The brain-derived neurotrophic factor gene confers susceptibility to bipolar disorder: evidence from a family-based association study. Am J Hum Genet 2002;71:651-655. [PubMed: 12161822]

Pang PT, Teng HK, Zaitsev E, et al. Cleavage of proBDNF by tPA/plasmin is essential for long-term hippocampal plasticity. Science 2004;306:487-491. [PubMed: 15486301]

Patterson S, Abel T, Deuel T, Martin K, Rose J, Kandel E. Recombinant BDNF rescues deficits in basal synaptic transmission and hippocampal LTP in BDNF knockout mice. Neuron 1996;16:1137-1145. [PubMed: 8663990] 
Pezawas L, Verchinski BA, Mattay VS, et al. The brain-derived neurotrophic factor val66met polymorphism and variation in human cortical morphology. J Neurosci 2004;24:10099-10102. [PubMed: 15537879]

Qui M-S, Green SH. NGF and EGF rapidly activate p21 ras in PC12 cells by distinct, convergent pathways involving tyrosine phosphorylation. Neuron 1991;7:937-946. [PubMed: 1764245]

Rosenblum K, Futter M, Voss K, et al. The role of extracellular regulated kinases I/II in late-phase longterm potentiation. J Neurosci 2002;22:5432-5441. [PubMed: 12097495]

Roux PP, Barker PA. Neurotrophin signaling through the p75 neurotrophin receptor. Prog Neurobiol 2002;67:203-233. [PubMed: 12169297]

Schacter DL, Wagner AD. Perspectives: neuroscience. Remembrance of things past. Science 1999;285:1503-1504. [PubMed: 10498535]

Schacter DL, Curran T, Reiman EM, Chen K, Bandy DJ, Frost JT. Medial temporal lobe activation during episodic encoding and retrieval: a PET study. Hippocampus 1999;9:575-581. [PubMed: 10560928]

Sen S, Nesse RM, Stoltenberg SF, et al. A BDNF coding variant is associated with the NEO personality inventory domain neuroticism, a risk factor for depression. Neuropsychopharmacology 2003;28:397-401. [PubMed: 12589394]

Shimizu E, Hashimoto K, Iyo M. Ethnic difference of the BDNF 196G/A (val66met) polymorphism frequencies: the possibility to explain ethnic mental traits. Am J Med Genet B Neuropsychiatr Genet 2004;126:122-123. [PubMed: 15048661]

Sklar P, Gabriel S, McInnis M, et al. Family-based association study of 76 candidate genes in bipolar disorder: BDNF is a potential risk locus. Brain-derived neutrophic factor. Mol Psychiatry 2002;7:579-593. [PubMed: 12140781]

Suter U, Heymach J, Shooter E. Two conserved domains in the NGF polypeptide are necessary and sufficient for the biosynthesis of correctly processed and biologically active NGF. EMBO J 1991;10:2394-2400.

Szeszko PR, Lipsky R, Mentschel C, et al. Brain-derived neurotrophic factor val66met polymorphism and volume of the hippocampal formation. Mol Psychiatry 2005;10:631-636. [PubMed: 15768049]

Teng HK, Teng KK, Lee R, et al. ProBDNF induces neuronal apoptosis via activation of a receptor complex of p75NTR and sortilin. J Neurosci 2005;25:5455-5463. [PubMed: 15930396]

Traverse S, Gomez N, Paterson H, Marshall C, Cohen P. Sustained activation of the mitogen-activated (MAP) kinase cascade may be required for differentiation of PC12 cells. Biochem J 1992;288:351355. [PubMed: 1334404]

Ventriglia M, Bocchio Chiavetto L, Benussi L, et al. Association between the BDNF 196 A/G polymorphism and sporadic Alzheimer's disease. Mol Psychiatry 2002;7:136-137. [PubMed: 11840305] 